\title{
Direct Analysis of Early Solar System Aqueous Fluids
}

\author{
M. E. ZOLENSKY ${ }^{1}$, R. J. BODNAR ${ }^{2}$, A. DOLOCAN ${ }^{3}, H$. \\ LAMADRID $^{4}$, Y. KEBUKAWA ${ }^{5}$, E. SENDULA ${ }^{2}$, Q. H.-S. \\ $\mathrm{CHAN}^{6}$
}

${ }^{1}$ ARES, NASA JSC, Houston TX 77058, USA, michael.e.zolensky@nasa.gov

${ }^{2}$ Dept. of Geosciences, Virginia Tech, Blacksburg VA 24061 USA, rjb@vt.edu; seszter1@vt.edu

${ }^{3}$ Texas Materials Institute, Univ. of Texas, Austin, TX 78712 USA, adolocan@austin.utexas.edu

${ }^{4}$ Dept. Geol. Sciences, Univ. of Missouri Columbia, Columbia MO 75211, USA, lamadridh@missouri.edu ${ }^{5}$ Faculty of Engineering, Yokohama National Univ., Yokohama 240-8501, Japan, kebukawa@ynu.ac.jp ${ }^{6}$ School of Physical Sciences, Open University, Milton Keynes, UK, queenie.chan@open.ac.uk

We lack fundamental information on early solar system aqueous fluids [1]. Fluid inclusions are present in carbonates, sulfides and halides in astromaterials, whose characterization is finally becoming feasible. The ordinary chondrite regolith breccias Monahans 1998 (H5) and Zag (H3-6) contain fluid inclusionbearing halite $(\mathrm{NaCl})$ crystals dated at $\sim 4.5$ billion years old $[2,3]$. Freezing studies to measure the eutectic temperature demonstrated that the brines likely contain divalent cations ( $\mathrm{Ca}, \mathrm{Mg}, \mathrm{Fe})$ [1]. Halite is effective at preservation (at least $250 \mathrm{MY}$ ) of organic phases and structures [4]. Thus, compositional data on fluid inclusions in halite will reveal unique information on the origin and activity of aqueous fluids in the early solar system, and interactions with organics.

To measure fluid compositions from individual fluid inclusions we performed TOF-SIMS depth profiling at ultra-high vacuum at $\sim 110 \mathrm{~K}$ using a $30 \mathrm{kV} \mathrm{Bi}^{+}$analysis ion beam and a $1 \mathrm{kV} \mathrm{O}_{2}^{+}$sputtering ion beam.

Halite fluid inclusion FIl contains $\mathrm{H}_{2} \mathrm{O}, \mathrm{K}, \mathrm{Na}, \mathrm{Cl}$ and $\mathrm{NaCl} \cdot 2 \mathrm{H}_{2} \mathrm{O}$. FI2 contains $\mathrm{H}_{2} \mathrm{O}, \mathrm{K}, \mathrm{Na}, \mathrm{Cl}, \mathrm{Al}, \mathrm{Fe}$, $\mathrm{Ca}, \mathrm{NaCl} \cdot 2 \mathrm{H}_{2} \mathrm{O}$ and $\mathrm{C}-\mathrm{N}-\mathrm{O}-\mathrm{H}$ species originating from organic molecules. Mass overlap with $\mathrm{NaOH}$ species prevented definitive identification of $\mathrm{Ca}$ in FI1.

[1] Brearley (2006) In Meteorites and the Early Solar System II, U. of A. Press, 587-624; [2] Zolensky et al. (1999) Science 285, 1377-1379; [3] Rubin et al. (2002) Meteoritics and Planetary Science 37, 125-142; [4] Satterfield et al. (2005) Geology 33, 265-268. 